\title{
The Effect of Integrating an Educational Robot with Hypermedia on Students' Acquisition of Scientific Concepts: The Case of Fifth-Grade Students
}

\author{
https://doi.org/10.3991/ijim.v15i11.18537
}

\author{
Aseel O. Ajlouni ( $\left.{ }^{凶}\right)$, Suhair Jaradat \\ The University of Jordan, Amman, Jordan \\ a.ajlouni@ju.edu.jo
}

\begin{abstract}
New educational technologies in terms of robots and hypermedia have growing considerations in education. They have been characterized as promising instructional technologies to enhance learning and rapid 21st-century skill acquisition, which has increased the theoretical literature in educational robots (ER) and hypermedia and their practical implementation in the context of education. Despite the educational interest in these technologies, there are limited studies that have examined their effect on primary students' acquisition of scientific concepts. This study's novelty is based on integrating ER with hypermedia to improve the acquisition of scientific concepts. The present study aimed to investigate the impact of integrating ER with hypermedia in the acquisition of scientific concepts among fifth-grade students $(\mathrm{N}=50)$ utilizing a quasi-experimental design with a control group (CG) and an experimental group (EG). The EG was taught using ERs and hypermedia, while the CG was taught using traditional instruction. Data were collected through administration of the presently developed scientific concept test as pretest and posttest. The findings revealed a significant development in the acquisition of scientific concepts among these fifth-grade students. These findings support that integrating ERs with hypermedia positively impacts students' acquisition of scientific concepts. Education ministries in general and science teachers, in particular, can use these results to improve opportunities for students to acquire scientific concepts.
\end{abstract}

Keywords - Robot, hypermedia, scientific concepts, science, instruction, WeDo 2.0

\section{Introduction}

The educational system has witnessed rapid advancement in educational technology, initiating curriculum reform as traditional instruction methods have been demonstrated to be inadequate and inefficient [1]. Learning in the 21st century must develop and foster students' skills through learning activities involving technology and digitalization [2]. The educational sector has witnessed progress in using multimedia, hypermedia, and educational robot (ER) in several disciplines. 
ER has become an essential part of the educational curricula in many countries; the interest in ER is considered vital for an efficient learning process in young children as it prepares students for 21 st-century requirements [3-5]. The integration of ERs in learning has several advantages: facilitating hands-on and minds-on activities, collaborative and project-based learning, making learning more enjoyable, and providing tangible learning materials [2], [6-7]. Hypermedia is used as an educational tool in classrooms. It is a mix of hypertext and multimedia technologies that provides different learning material representations with nonlinear navigation. Researchers have found a positive impact on the learning and teaching process; it has been shown to improve students' understanding, problem-solving and scientific processing skills, and academic performance [8-14]. Based on these studies, integrating ER and hypermedia in education is beneficial to support the learning process.

Science education is considered an essential portion of 21 st-century education [15]; despite this, some issues need to be considered, such as students' motivation toward science and their difficulty comprehending scientific concepts, especially abstract ones. Some studies have demonstrated that students' misconceptions can affect their understanding and learning achievements [16-22]. Moreover, some countries have revealed a weakness among their students in science outcomes following the Program for International Student Assessment and the Trends in International Mathematics and Science Study (TIMSS) [20-21].

In Jordan, the 2015 TIMSS results revealed weaknesses among science students, which fell by 23 points from 2011 to 2015 [21]. Al-Mansour [23] highlighted an urgent need to enhance the Jordanian science curriculum and incorporate digital skills into its study areas. Students to better understand science have been recommended to focus on scientific concepts that serve as the fundamental building blocks of scientific theories and permit clarifying and predicting many scientific phenomena [24]. Researchers have integrated technologies such as ERs and hypermedia into science learning and teaching processes to accomplish this. These issues highlight a particular need in Jordan for research on enhancing students' scientific concept acquisition and the impact of ER and hypermedia use in science education. Our literature review found no studies that specifically addressed the effect of integrated ER with hypermedia. The present study provides data about the effectiveness of integrating ER with hypermedia in the acquisition of scientific concepts, which adds to the literature on this issue and may encourage science teachers to integrate this teaching practice.

\subsection{Aim of the study}

This study aimed to investigate the effects of integrating ERs with hypermedia in the science curriculum to acquire scientific concepts related to motion and force by fifthgrade students in Jordan. We sought to answer this research question: Are there statistically significant differences $(\alpha=0.05)$ in the acquisition of scientific concepts among fifth-grade students attributed to the teaching methods (traditional vs. ER with hypermedia)? 


\section{$2 \quad$ Literature Review}

\subsection{Scientific concepts acquisition process}

The concept sometimes refers to an idea held in an individual's mind [25]; it is a set of specific objects, symbols, or events that are grouped based on shared characteristics and referenced by a specific name or symbol [26]. Students have learned a concept when they correctly classify the class membership of the same symbol, event, or object [25]. More specifically, scientific concepts are considered the base structures of science [27]. Sufficient knowledge of scientific concepts is a vital prerequisite for solving scientific problems, but many students experience great difficulty learning and acquiring the basic scientific concepts [24]. It is widely accepted that students in early grades have difficulty comprehending the concepts of force and motion [28].

According to Piaget's cognitive development theory, fifth-grade students aged between 10 and 11 years represent a transitional age group located in the last portion of the concrete operational stage (7-11 years); in this stage, students can solve problems related to things that are concrete [18]. These students experience difficulty with deductive reasoning and understanding and utilizing common sense, which is not yet fully adapted [29]. Some concepts interconnect with other concepts that make them more challenging to comprehend, such as the physical concept of motion [30-31]. Well, design-based learning methods facilitate student learning and understanding of disciplinary concept connections [33]; however, according to Piaget, instructional designers should provide a rich learning environment with physical experiences (e.g., hands-on activities and supporting materials) that serve to introduce abstract concepts through concrete, physical examples [34-35]. Students at the concrete operational stage require teaching methods and strategies that emphasize learning through visual material where the problematic concept can be learned with metaphors [32-36]. Some researchers have developed instructional approaches such as meta conceptual teaching practices and the 5E Learning Cycle [37-38] as they attempted to integrate technological tools that enhance the acquisition of scientific concepts [39-43]. Despite this work, there remains the need to support students in comprehending and acquiring scientific concepts. More research in the acquisition of scientific concepts facilitated by technological tools such as ERs and hypermedia is needed.

\subsection{Educational robots and science education context}

ERs have attracted the attention of teachers and researchers in various countries across the world and have been used as learning tools for various areas of knowledge such as mathematics, physics, language, programming, and music [3-4], [7], [44-46]. ERs have been part of the national curriculum in some countries, while other countries have limited robot-based curricula to robot camps, enrichment activities, or after-school classes [47-48]. However, robot Olympics and national and international ER competitions have appeared in most countries to encourage science, technology, engineering, 
and mathematics (STEM) learning [49]. The literature shows that ER is one of the leading emergent technologies used for teaching and learning science concepts in K-12 classrooms [50] to prepare students for 21st-century skills and requirements [4-5], [51].

ER is a valuable learning tool for project-based learning in which STEM, coding, computational thinking, and engineering skills can be incorporated into one project. Such a learning experience offers students an opportunity to investigate how technology works in a real-life context through the act of making and think deeply and apply the skills and knowledge learned in school in a meaningful and enjoyable way [52]. ERs can foster collaboration skills, problem-solving, and critical and innovative thinking. They can also enhance the learning experience through hands-on and mind-on learning; provide a fun, exciting, and engaging learning environment; and motivate students to learn, provide opportunities to link learning with practice, develop students' technological competencies, enhance student motivation to learn, encourage imagination, improve academic achievement [8], [39], [52-57].

Integrating ER in science education offers rich learning opportunities to engage students in the real world, help them construct conceptual understanding, and gain a good understanding of the underlying concepts; integrating ER into science activities helps students explore new concepts [58-59]. ERs have been integrated into educational processes based on Papert, Vygotsky, and Piaget's work to build meaningful learning experiences [48].

Scaradozzi and colleagues [60] pointed out that the integration of an ER requires the simultaneous interaction of the students, the teacher, and the technology with each other. Additionally, they developed principles for educational robotics applications (ERAs), forming a general framework to guide educators and designers in the employment and evaluation of ER use in educational environments. The ERAs consist of ten principles distributed into three main axes: technology, student, and teacher [61]. Students can interact, engage, motivate, and learn more about their real-world by working with ER; they can interact and control ER using programming languages. Some of the current ERs systems are BeeBot, LEGO® WeDo 2.0, Arduino®, and Edison.

LEGO's ER is appropriate for beginners since many students are familiar with LEGO from an early age. LEGO's ER has several products targeted at preschool, elementary school, and middle schools, such as Mindstorms EV3, NXT, and WeDo 2.0. Visual block-based programming environments such as WeDo 2.0 and Scratch are considered suitable for young children and novice programmers [4], [62-64]. They are easy to learn as they permit students to test and experiment with programming structures by assembling pieces of code by dragging and dropping blocks onto the programming canvas to generate program strings. Since the combination of new interactive technologies and the appropriate pedagogical method facilitates students' learning [65], teachers should utilize the appropriate ER and pedagogy for their targeted students.

\subsection{Hypermedia and science education context}

Hypermedia was presented in the scientific literature about 55 years ago as a combination of multimedia and hypertext technologies [66-68]. It is defined as an interactive software system that allows users to freely browse and navigate hyperlink information 
utilizing user-selected, path-like, interactive websites and interactive courseware [69], which provides flexibility to users in nonlinear ways through link-related items [70]. Therefore, hypermedia merges multimedia elements to allow learners to interact with content and navigate through it in nonlinear paths according to their needs. Hypermedia has many advantages. For example, it facilitates concurrent use, easy modification and tracking of browsing activities, abstraction of information, simulations of real situations, ease of adding references, modularity and consistency of information, and cooperative work [68].

Hypermedia is a promising approach to knowledge transfer in the educational domain [71]. It has emerged in the field of education as a learning tool [72]. Hypermedia helps students gain not only basic knowledge but also increased understanding [73]. Further, it offers lower-achieving students the immediate advantage of catching up somewhat with higher-achieving peers [74]. In science education, hypermedia helps students to understand complex systems as it presents complex concepts in interactive simulation forms, engages and helps them to understand the concepts deeply, makes them the center of their learning, helps them adapt, and supports them by improving ideas, concepts, and feedback [11], [75-76]. Despite this, hypermedia implementation has faced some barriers such as disorientation, cognitive overload problems, insufficient information access, and prior user knowledge [77-80]. Accordingly, instructional designers and teachers should consider and address them when designing, implementing, and using hypermedia learning environments.

\subsection{Previous studies}

Previous studies employing ERs in $\mathrm{K}-12$ settings have addressed several variables, including skills, psychological variables, and academic achievement [81-87]. Studies support that robotics can significantly impact education and positively impact students' academic performance [88-90]. Sullivan and Bers [91] found that pre-kindergarten children can learn to use ERs and mastering robot programming skills. Papadakis [64] investigated visual block-based programming environments and found that they are suitable for young children, help novice students generate their programs more accessibly, and teach programming using Scratch and App Inventor improved their performance on programming. Bers and Sullivan [91] discovered the efficiency of ER used for PK2 students; their results showed that all students could master basic robotics and programming skills, while older students could master increasingly complex concepts using the same ER within the same amount of time.

Baddeley [92] investigated the positive effect of ER use on students' acquisition of physical concepts. Jaipal-Jamani and Angeli [93] showed that ER activity was an efficient instructional strategy to enhance interest in robotics and develop science concepts among elementary students. Krishnamoorthy and Kapila [94] employed ERs to support K-12 students' acquisition of STEM concepts and found that the ERs enhanced students' understandings of STEM concepts and increased their academic performance. Saez-Lopez and colleagues [95] explored the positive effects of ER use on sixth-grade elementary students' understandings of mathematical concepts. 
Other researchers have conducted studies that employed hypermedia in science classrooms to show their impact on the learning and teaching process; Marchisio [96] developed a hypermedia-assisted self-study system called "Del átomo al sólido" to be used as a teaching resource for physics curricula; students using this system showed increased positive attitudes and motivation. Liu [76] found that a hypermedia learning environment positively impacted sixth-grade students in that it increased their sciencerelated knowledge, intrinsic motivation, and attitudes toward science. Amin and Mahmud [97] developed a valid and reliable hypermedia learning instrument for physics curricula to motivate students and enhance their problem-solving skills. Bunga and colleagues [10] examined the effects of using a hypermedia learning instrument in physics curricula and found that it improved scientific processing skills. Ajlouni and Jaradat [8] examined the effect of a pedagogical hypermedia environment in the science discipline (PHFSD) among fifth-grade students and found that it enhanced the acquisition of scientific concepts.

The results of previous studies highlight the overwhelmingly positive impact of integrating ERs in science education as well as hypermedia. In sum, technology-supported science education has been an effective way to motivate students, engage them in learning science, and understand its concepts. The benefits of using hypermedia in scientific concepts related to its capability to animate scientific processes, concrete concepts, and complex systems - making it a valuable instructional tool in learning scientific concepts. ERs permit hands-on experience and learning activities that support learning by multiple stimuli that help students remember what they have learned and construct their knowledge. To gain the benefits of both technologies in learning and teaching scientific concepts, they should be integrated. No research study to date has investigated the impact of integrating hypermedia with ERs on students' acquisition of scientific concepts.

\section{Methodology}

The present study adopted a quasi-experimental approach with two groups - an experimental group (EG) and a control group (CG) - to obtain information about the phenomenon under study. The researchers obtained approval to conduct this study from the Ministry of Education in Jordan, and the psychometric properties (i.e., validity and reliability) of the instruments and materials developed for this study were ensured. The school understudy was purposively selected with attention to the availability of resources necessary to conduct the study, including Wi-Fi services, ER kits, an interactive smartboard, tablets, and more than 40 fifth-grade students. Two classes were randomly selected and assigned to the EG and the CG, with 25 female students assigned to each group. The same science teacher taught all students. The EG was taught a unit on motion and force using ERs and hypermedia, while the CG was taught the same unit using traditional instruction. The scientific concept test (SCT) for motion and force was developed and administrated to both groups at pretest and posttest points. The research design is symbolized as follows: 
EG: $\mathrm{O} \quad \mathrm{X} 1 \quad \mathrm{O}$

CG: $\mathrm{O} \quad \mathrm{X} 2 \quad \mathrm{O}$

$\mathrm{O}, \mathrm{X} 1$ and $\mathrm{X} 2$ represent the SCT, instruction involving ERs with hypermedia, and traditional instruction. This study's dependent variable was student acquisition of scientific concepts, while the independent variables were the two teaching methods. Descriptive and inferential data analyses were used to analyze data collected through the pretest-posttest SCTs for each group. Statistical Package for the Social Sciences (SPSS) software was used to analyze the collected data and demonstrate the impact of ER and hypermedia use on students' acquisition of scientific concepts.

\subsection{Participants and setting}

The study sample consisted of 50 fifth-grade students enrolled in the first semester of the 2019/2020 academic year in a private school in Amman, Jordan's capital. The age of the participants was between (10-11) years, and all were female. The pilot sample consisted of 45 fifth-grade students whose age was between (10-11) years at another private school in Amman. The CG was taught the motion and force topic of a science textbook for fifth-grade students using traditional instruction. Students in the CG used the traditional science textbook along with the worksheets that covered material from the textbook and science laboratory tools, such as a spring scale measure, as they cooperatively worked in small groups during class sessions. The science teacher in the CG used the interactive smartboard for writing and presented some YouTube videos related to the motion and force topic; the EG was taught the same topic by the same teacher using ERs and hypermedia as presented in Figure 1. The teacher's role was limited to facilitating the learning process through daily questioning, answering, discussion, and assistance. The topic was implemented over eight weeks, totaling 18 hours for each group.

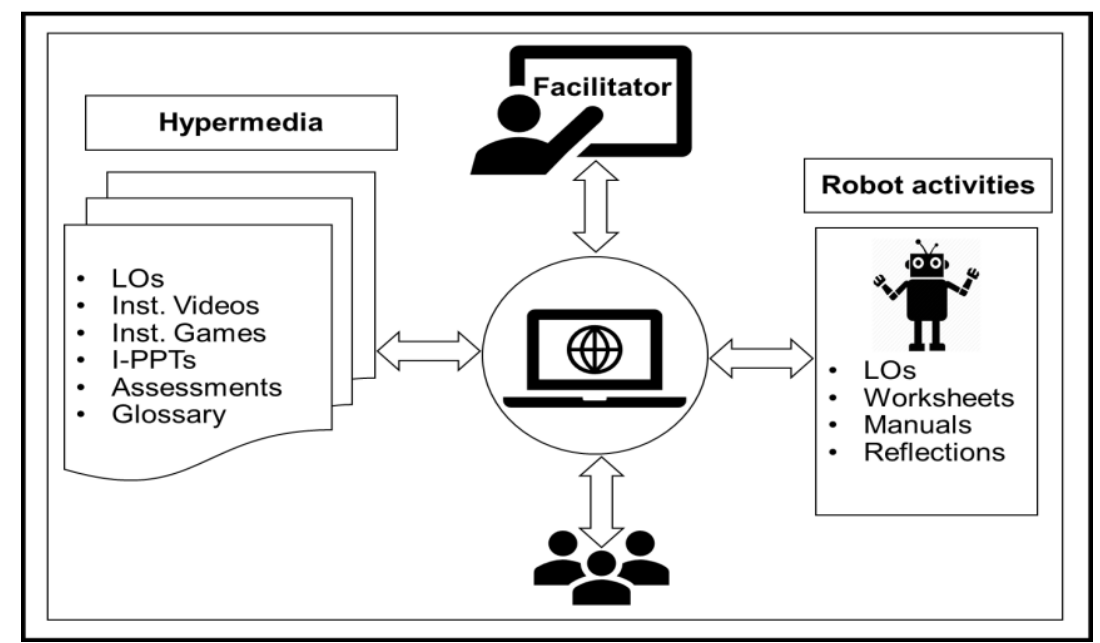

Fig. 1. ER and Hypermedia Instructions 
Students in the EG used a pedagogical hypermedia environment for the scientific discipline (PHFSDП) and ERs in their 45-minute science class; they were able to access PHFSD $\prod$ outside the classroom at any time. The science teacher used PHFSD $\Pi$ in the place of traditional instructional materials. Students worked in the classroom and had access to tablets and ERs, and were assigned to groups to complete ER activities collaboratively. Before the lesson, students could access PHFSDП from their homes to recall prerequisite knowledge from instructional videos and an instructional game. During class, the teacher opened a discussion on the lesson topic using an interactive PowerPoint with videos embedded in the hypermedia. Then, students worked collaboratively in small groups to complete ER activities and related worksheets. Students could navigate the hypermedia for enrichment and remediation materials and assessment tools as needed from outside the class sessions.

The hypermedia system used in this study, PHFSDП, was developed by [31] as a doctoral dissertation in educational technology at the University of Jordan. The learning outcomes of PHFSDП covered the motion and force topic for fifth-grade students. PHFSD $\prod$ was evaluated and reviewed by a panel of 11 specialists and tested on a pilot sample of 5 fifth-grade students; the scores for all evaluation factors were above the effectiveness threshold set to $80 \%$. This shows that the PHFSDП is an efficient teaching and learning tool and judged valid by the specialists' panel. The pilot sample was taught the selected topic using PHFSDП; their comments were undertaken to revise the tool (i.e., modify the time allocated for quizzes and provide additional pre-requested material) [39]. This tool was based on the fifth-grade science curriculum, constructivist principles, and educational hypermedia design guidelines. Hypermedia contains a set of educational elements related to motion and force presented in multi-representational formats and allows for nonlinear content navigation to accommodate students' differing abilities and learning strategies [39]. It includes remedial, enrichment, and prerequisite material and assessment tools, such as quizzes and worksheets that students can access as needed. PHFSDП is hosted at http://www.jsg5b.com.

The ERs used in this study were WeDo 2.0 robot kits produced by the LEGO Education Group. This kit is suitable for school. Each kit consisted of sorting trays, labels, a smart hub, a medium motor, a motion sensor, and 280 bricks. WeDo 2.0 robots are programmable by WeDo 2.0 software, easy-to-use software that makes coding achievable for elementary students. This software was installed on the tablets that students used; it permitted students to create their block coding string by dragging and dropping the icon and then controlling the ERs.

The ER activities were developed by [31] as products of a doctoral dissertation in educational technology at the University of Jordan. It was designed according to ERA principles. The science curriculum and constructivist activities were reviewed and approved by a panel of 14 experts specializing in educational technology, teaching science, curricula, artificial intelligence, robotics science, and supervisors and teachers of science curricula.

The ER activities were also implemented with five fifth-grade students outside the participant sample of the present study to ensure the appropriateness of the targeted audience's activities and the adequacy of the required amount of time to be spent on ER activities. Each ER activity consisted of learning outcomes, worksheets, manuals, and 
reflection forms embedded in the hypermedia. Students worked in groups during the class sessions to build robots and program them to solve the worksheets. The students learned scientific concepts through these inquiry-based, hands-on activities.

\subsection{Study instrument}

The scientific concepts test was developed to collect the data necessary to reveal integrating ER with hypermedia on student acquisition of scientific concepts (SCT). This SCT assessed students' understanding of the concepts covered in the motion and force unit based on (a) the literature on scientific concepts that involved a synthesis of existing research [25], [99-98], (b) a content analysis of the force and motion unit of a fifth-grade science textbook, and (c) the level of intended learning outcomes associated with the scientific concepts that students are expected to master in the fifth grade. The SCT consisted of 20 multiple-choice questions. Each question had three answer options, one of which was correct. The SCT scores ranged between 0 and 20, and each valid answer contributed one point to the overall score. The acquisition of scientific concepts by the students was inferred in light of the test scores.

A panel of 20 experts ensured the content and face validity of the test from Jordanian universities with experience and specialization in the field of curricula, methods of teaching science, measurement, and evaluation, as well as several supervisors and teachers of science curricula from private schools and the Ministry of Education. These experts examined how well the questions of the SCT represented the examined theoretical constructs. Specifically, they examined whether these questions matched the concepts under the study's conceptual domains, their suitability for the present study, and the extent to which they represented the levels (i.e., definition, example and non-example, and characteristics) of each concept. The panel of experts individually rated the appropriateness and clarity of each question and the three multiple-choice answer options. They were also asked to provide comments specific to the format, language, clarity, and other vital elements for evaluating the proposed instrument, which would help teachers assess a student's understanding and acquisition of the scientific concept. Their comments were used to revise the proposed instrument and generate a final version of SCT.

To ensure the reliability of the SCT, its test-retest reliability was determined by administering it to the pilot sample, which consisted of 45 fifth-grade students outside the study sample, and then re-administering it three weeks later. A Pearson correlation coefficient of 0.96 was calculated between the initial test and the retest results. The internal consistency was calculated as 0.82 using Cronbach's alpha equation. According to these values, the SCT has an acceptable level of reliability for this study.

The difficulty and discrimination indices for the SCT questions were calculated using data collected from the pilot sample. The difficulty index values for 17 questions ranged between 0.79 and 0.31 ; these values were considered acceptable for this study as they indicated variation in the difficulty level of the SCT. Three questions $(10,14$, $\& 19)$ were recognized as highly difficult, with difficulty indexes of $0.10,0.13$, and 0.08 , respectively. The discrimination index values ranged from 0.21 to 0.67 , indicating 
that the SCT could distinguish between the students who were able to answer the questions correctly and those who were less able. The discrimination index of the SCT was considered acceptable for this study as it was positive and greater than 0.20 . Table 1 shows the difficulty and differentiation index values of the SCT. According to these findings, the SCT is a valid and reliable instrument; it can be used to assess a student's acquisition of a scientific concept.

Table 1. Demographic Discrimination and Difficulty Index of the SCT

\begin{tabular}{|c|c|c|}
\hline Question No & Discrimination Index & Difficulty Index \\
\hline 1 & 0.32 & 0.90 \\
\hline 2 & 0.47 & 0.69 \\
\hline 3 & 0.21 & 0.56 \\
\hline 4 & 0.36 & 0.79 \\
\hline 5 & 0.24 & 0.54 \\
\hline 6 & 0.67 & 0.49 \\
\hline 7 & 0.23 & 0.72 \\
\hline 8 & 0.55 & 0.41 \\
\hline 9 & 0.58 & 0.46 \\
\hline 10 & 0.22 & 0.10 \\
\hline 11 & 0.29 & 0.64 \\
\hline 12 & 0.47 & 0.38 \\
\hline 13 & 0.33 & 0.51 \\
\hline 14 & 0.37 & 0.13 \\
\hline 15 & 0.45 & 0.38 \\
\hline 16 & 0.38 & 0.31 \\
\hline 17 & 0.57 & 0.46 \\
\hline 18 & 0.25 & 0.59 \\
\hline 19 & 0.34 & 0.08 \\
\hline 20 & 0.36 & 0.44 \\
\hline
\end{tabular}

\subsection{Data analysis}

The researchers used descriptive and inferential data analyses using SPSS to conduct an ANCOVA and calculate means, standard deviations, and adjusted means to investigate the effect of integrating ER with hypermedia on the acquisition of scientific concepts among these primary school students in Jordan.

\section{$4 \quad$ Results and Discussion}

The students' answers on the SCT were analyzed, and the effect of integrating ERs with hypermedia on students' acquisition of the scientific concept was assessed. The means and standard deviations of the fifth-grade students' pretest and posttest SCT scores were calculated (see Table 2). The two groups achieved similar mean scores on the pretest SCT, with a total M of 5.66 and an SD ranging from 2 to 72 . These values were relatively low, indicating that the students had difficulty understanding scientific 
concepts. This result is in line with the results of [100]. The M posttest SCT scores indicated that the two groups' levels of concept acquisition differed by 4.36 in favor of the EG.

Table 2. Means and Standard Deviations of Fifth-Grade Students' Pretest and Posttest SCT Scores

\begin{tabular}{|l|c|c|c|c|c|}
\hline \multirow{2}{*}{ Group } & \multirow{2}{*}{$\boldsymbol{N}$} & \multicolumn{2}{c|}{ Pretest } & \multicolumn{2}{c|}{ Posttest } \\
\cline { 3 - 6 } & & $\boldsymbol{S D}$ & $\boldsymbol{M}$ & $\boldsymbol{S D}$ & $\boldsymbol{M}$ \\
\hline Experimental & 25 & 1.29 & 5.60 & 0.89 & 17.28 \\
\hline Control & 25 & 1.21 & 5.72 & 2.10 & 12.92 \\
\hline Total & 50 & 1.24 & 5.66 & 2.72 & 15.10 \\
\hline
\end{tabular}

Note. $\mathrm{N}=$ number of students in the group.

To answer the study's research question, ANCOVA was conducted to investigate this statistical difference; and the partial eta squared ( $\eta 2)$ was extracted to investigate the magnitude of the effect of the teaching method on the acquisition of scientific concepts. The results of these analyses (see Table 3 ) indicate a statistically significant $(\alpha=$ $0.05)$ difference in the fifth-grade students' posttest SCT scores between different teaching methods $(F=91.183, p=0.000)$. Additionally, $\eta 2$ reached 0.66 , meaning that $66 \%$ of the posttest SCT scores' variation can be ascribed to the teaching method's effect. To determine which group was favored by this difference, the posttest scores' adjusted means were calculated. The adjusted mean of the posttest SCT scores of the EG reached 17.29 while the $C G$ was 12.91 ; both indicated a standard error of 0.32 .

Table 3. Results of an ANCOVA of Fifth-Grade Students' Posttest SCT Scores

\begin{tabular}{|l|c|c|c|c|c|c|}
\hline Source of Variation & Sum Square & Df & Mean Square & F & Sig & (ๆ2) \\
\hline Pretest & 1.684 & 1 & 1.684 & 0.642 & 0.427 & 0.013 \\
\hline Teaching Method & 239.010 & 1 & 239.010 & 91.183 & 0.000 & 0.660 \\
\hline Error & 123.196 & 47 & 2.621 & & & \\
\hline Adjusted Total & 362.500 & 49 & & & & \\
\hline
\end{tabular}

Note. Sig = significant, $\mathrm{Df}=$ degrees of freedom, $\mathrm{F}=\mathrm{F}$-test.

According to these results, ERs with hypermedia fostered better acquisition of scientific concepts than traditional instruction. Specifically, force and motion included fundamental physics concepts such as force, frictional force, gravity, distance, kinetic energy, and speed. The literature provides evidence that students have difficulty comprehending force and motion concepts [28]. Gravity and friction are abstract concepts that need more examples and physical experience with touchable objects to comprehend. Moreover, some physics concepts have interconnections that depend on other foundational physics concepts, requiring students to invoke prerequisite knowledge. For example, the acquisition of the speed concept requires invoking both distance and time concepts. These interconnected and abstract concepts are considered more challenging to learn than other concepts [30-31], [101]. Hence, the acquisition of such scientific concepts can be enhanced using ERs with hypermedia. 
The acquisition of motion and force concepts starts from the image-schemas that convert previous experiences into abstract knowledge [40]. The PHFSDП invokes the required schema and provides a simulation that effectively helps students build meaningful connections between mental representations of force and motion. Also, ER activities give students real-world experiences of motion and force. These demonstrated the enhancement of the acquisition among the EG compared to the $\mathrm{CG}$.

ERs and hypermedia provide an active learning environment rich in resources. The WeDo 2.0 robot kit provided students with the opportunity to implement their learning activities in a practical, touchable way. The hands-on ER activities engaged the students in their learning tasks to help them (a) express their ideas and test their solutions in a real-life context and (b) learn and acquire scientific concepts in a sensory manner. Specifically, the students utilized abstraction, which is appropriate to fifth-grade students' cognitive abilities according to Piaget's cognitive development classifications. Sensory experience is necessary for students in this age group to learn abstraction [18].

In addition to the robot activities, the hypermedia provided multiple representations of students' content to suit their favored learning style. The use of hypermedia rendered the examples and non-examples, characteristics, and definitions of the topic concepts clearer and easier to understand according to the students' differing cognitive abilities. The hypermedia also provided multiple ways of navigating and browsing content, thus supporting both dependent and independent learning styles. As it provides metaphors, simulations, and visual representations enable students to explore spatial perspectives to enhance their understanding of abstract concepts [102]. Finally, hypermedia allowed the students to access the course content flexibly, thus facilitating the learning process.

The findings of this study are in line with the results of several other studies relating to hypermedia. First, Ajlouni and Jaradat [8] found a significant positive impact of hypermedia on acquiring transparent science concepts. Then, Bunga et al. [10] showed that hypermedia increased students' scientific processing skills and made physics content easier to understand. Amin and Mahmud [97] found that physics content made easy to understand by hypermedia enhanced students' problem-solving skills. Finally, Liu [76] found that a hypermedia-based learning environment increased the scientific knowledge of sixth-grade students.

Previous research has indicated that ERs have positive effects on student acquisition of physical concepts. For example, studies by Badeleh [92], Krishnamoorthy, and Kapila [94] found that ERs enhanced K-12 students' understanding of STEM concepts and increased their academic performance. This is consistent with the findings of JaipalJamani and Angeli [93] on robotic activity to develop an understanding of science concepts. The results of the studies above are in line with the present findings.

This study demonstrates that the use of ER with hypermedia was favorable to the students by evaluating their performance through the SCT, which is reflected by assessing their acquisition and understanding of the selected unit's scientific concepts. Accordingly, the integration of hypermedia and ERs enhanced the students' acquisition of scientific concepts. 


\section{Conclusion}

Teachers can enhance the teaching and learning process by integrating pedagogical and technological advancements in school activities and practices. The present study addressed the effects of integrating ERs and hypermedia on scientific concept acquisition among fifth-grade students. The hypermedia system used in this study, called PHFSD $\Pi$, is a reliable and valid system based on the Jordanian Ministry of Education's science curriculum, constructivist principles, and educational hypermedia guidelines. This study's ER activities were based on ERA principles and evaluated by a panel of experts and targeted audience members [39].

Hypermedia provides nonlinear navigation and multi representation of course content; it flexibly facilitates self-learning opportunities because students can access hypermedia both inside and outside of class sessions at any time. Hypermedia allows students to access prerequisite information, new knowledge, remediating materials, and enriching materials in a multi-representational format to accommodate variations in ability and learning style. Additionally, ER science activities provide students with the opportunity to engage in hands-on activities with touchable objects in cooperative groups, thus helping them acquire scientific concepts according to their cognitive ability in a practical social context.

This study's findings showed that fifth-grade students taught using ERs and hypermedia had significantly increased their knowledge of scientific concepts from pretest to posttest and positively impacted their acquisition of scientific concepts. This study's findings may encourage teachers to integrate ERs with hypermedia to increase their students' acquisition and understanding of specific scientific concepts.

This study was implemented with 50 female fifth-grade students at a private school in Amman over 18 hours of in-class time and use of the PHFSDП through the teaching and learning process. Despite the study sample's limitation, the findings serve as evidence of the effectiveness of integrating ERs and hypermedia in improving students' acquisition of scientific concepts. Future studies might be designed to implement different samples, dependent variables, and disciplines to use other hypermedia in the learning process.

The implications of this study should encourage teachers to update their practice and activities inside and outside the classroom through hypermedia with educational robots because this method facilitates the construction of innovative educational experiences that help in the acquisition of scientific concepts. Finally, teachers can use hypermedia and educational robots to create new educational virtual spaces and touchable physical experiences. In particular, the use of the WeDo2.0 robot with PHFSD $\prod$ enhanced the acquisition of scientific concepts in the science discipline among these fifth-grade students. 


\section{References}

[1] E. Zaneldin, W. Ahmed, and B. El-Ariss, "Video-based e-learning for an undergraduate engineering course," E-Learn. digit. Media, vol. 16, no. 6, pp. 475-496, 2019. https://doi.org/10.1177/2042753019870938

[2] A. Latip, Y. Andriani, S. Purnamasari, and D. Abdurrahman, "Integration of educational robotic in STEM learning to promote students' collaborative skill," Journal of Physics: Conference Series, vol. 1663, no. 1, p. 012052, 2020. https://doi.org/10.1088/17426596/1663/1/012052

[3] P. Dorouka, S. Papadakis, and M. Kalogiannakis, "Tablets and apps for promoting robotics, mathematics, STEM education and literacy in early childhood education," International Journal of Mobile Learning and Organisation, vol. 14, no. 2, pp. 255-274, 2020. https://doi.org/10.1504/ijmlo.2020.10026334

[4] S. Lindsay and K. G. Hounsell, "Adapting a robotics program to enhance participation and interest in STEM among children with disabilities: a pilot study," Disabil. Rehabil. Assist. Technol., vol. 12, no. 7, pp. 694-704, 2017. https://doi.org/10.1080/17483107.2016. $\underline{1229047}$

[5] S. Papadakis, "Robots and robotics kits for early childhood and first school age," International Journal of Interactive Mobile Technologies (IJIM, vol. 14, no. 18, pp. 34-56, 2020. https://doi.org/10.3991/ijim.v14i18.16631

[6] A. Chatzopoulos, M. Kalogiannakis, S. Papadakis, M. Papoutsidakis, D. Elza, and S. Psycharis, "DuBot: An open-source, low-cost robot for STEM and educational robotics," in Handbook of Research on Using Educational Robotics to Facilitate Student Learning, IGI Global, 2021, pp. 441-465. https://doi.org/10.4018/978-1-7998-6717-3.ch018

[7] S. E. Jung and E. S. Won, "Systematic review of research trends in robotics education for young children," Sustainability, vol. 10, no. 4, p. 905, 2018. https://doi.org/10.3390/su100 $\underline{40905}$

[8] A. O. Ajlouni and S. A. Jaradat, "The Effect of Pedagogical Hypermedia on Acquisition of Scientific Concepts among Primary School Students," International Journal of Education and Practice, vol. 8, no. 3, pp. 615-624, 2020. https://doi.org/10.18488/journal. 61.2020.83.615.624

[9] O. A. Ajlouni and A. S. Jaradat, "Teaching science with technology: A pedagogical hypermedia for the science discipline," International Journal of Psychosocial Rehabilitation, vol. 8, no. 24, pp. 13900-13914, 2020.

[10] O. Aksit and E. N. Wiebe, "Exploring force and motion concepts in middle grades using computational modeling: A classroom intervention study," J. Sci. Educ. Technol., vol. 29, no. 1, pp. 65-82, 2020. https://doi.org/10.1007/s10956-019-09800-z

[11] B. Amin, A. Haris, and A. Swandi, "Implementation of physics learning instrument based on hypermedia to increase science process skill," Indonesia: Yogyakarta State University, 2017.

[12] M. O. Abanikannda, "Enhancing effective chemistry learning through hypermedia instructional mode of delivery," Eur. J. Educ. Res., vol. 5, no. 1, pp. 27-34, 2016. https://doi.org/10.12973/eu-jer.5.1.27

[13] M. O. Abanikannda, "Effectiveness of hypermedia and multimedia learning strategies on the academic performance of chemistry students in Nigeria," Lab. Educ., vol. 7, pp. 201214, 2019. https://doi.org/10.4467/25439561le.19.011.11528

[14] G. Lu, H. Wan, and S. Liu, "Hypermedia and its application in education," EMI Educ. Media Int., vol. 36, no. 1, pp. 41-45, 1999. 
[15] N. R. Council, Exploring the Intersection of Science Education and 21st Century Skills: A Workshop Summary. Washington, DC, USA: National Academies Press, 2010.

[16] M. Kalogiannakis, S. Papadakis, and A.-I. Zourmpakis, "Gamification in science education. A systematic review of the literature," Educ. Sci. (Basel), vol. 11, no. 1, p. 22, 2021. https://doi.org/10.3390/educsci11010022

[17] O. Aksit and E. N. Wiebe, "Exploring force and motion concepts in middle grades using computational modeling: A classroom intervention study," J. Sci. Educ. Technol., vol. 29, no. 1, pp. 65-82, 2020. https://doi.org/10.1007/s10956-019-09800-z

[18] S. R. Ghazi, K. Ullah, and F. A. Jan, "Concrete operational stage of Piaget's cognitive development theory: An implication in learning mathematics," Gomal University Journal of Research, vol. 32, no. 1, pp. 9-20, 2016.

[19] A. Unahalekhaka, I. Radu, and B. Schneider, "How augmented reality affects collaborative learning of physics: A qualitative analysis," Lyon, 2019.

[20] H. Eijkelhof, "Curriculum policy implications of the PISA scientific literacy framework," 2014, pp. 26-33.

[21] M. O. Martin, I. V. S. Mullis, P. Foy, and M. Hooper, "TIMSS 2015 Internation-al Results in Science." 2016.

[22] A. Ewais, R. Hodrob, M. Maree, and S. Jaradat, "Mobile learning application for helping pupils in learning chemistry," Int. J. Interact. Mob. Technol., vol. 15, no. 01, p. 105, 2021. https://doi.org/10.3991/ijim.v15i01.11897

[23] A. C. Al-Mansour, "Inclusion of 21st-century skills in the content of science textbooks at the basic education stage," Al Al-Bayt University, 2018.

[24] F. Reif, "Instructional design, cognition, and technology: Applications to the teaching of scientific concepts," J. Res. Sci. Teach., vol. 24, no. 4, pp. 309-324, 1987. https://doi.org/10.1002/tea.3660240405

[25] M. D. Merrill and R. D. Tennyson, "Teaching concepts: An instructional design guide." Educational Technology Publications, New Jersey, 1977.

[26] M. D. Merril, R. D. Tennyson, and L. O. Posey, Concept teaching: An instructional design guide, 2nd ed. New York: Englewood Cliffs, 1992.

[27] M. Zaytoon, Methods of Teaching Science. Amman, Jordan: Dar Al-Shorok Publishing Distribution \& Printing, 2013.

[28] A. Candan, L. Türkmen, and O. Çardak, "The effects of concept mapping on primary school students' understanding of the concepts of force and motion," Journal of Turkish Science Education, vol. 3, no. 1, p. 28, 2006.

[29] S. A. McLeod, Concrete Operational Stage. Retrieved from http://www.simplypsychology. org/concrete-operational.html, 2010.

[30] M. Erfan and T. Ratu, "Analysis of student difficulties in understanding the concept of newton's Law of Motion,” JIPF (J. Ilmu Pendidik. Fis.), vol. 3, no. 1, p. 1, 2018. https://doi.org/10.26737/jipf.v3i1.161

[31] F. Mufit, "A study about understanding the concept of force and attitude towards learning physics on first-year students in the course of General Physics; As preliminary investigation in development research," INA-Rxiv, 2019. https://doi.org/10.31227/osf.io/8n6ep

[32] P. Sutherland, "The application of Piagetian and Neo-Piagetian ideas to further and higher education,” Int. J. Lifelong Educ., vol. 18, no. 4, pp. 286-294, 1999. https://doi.org/10.1080/ $\underline{026013799293702}$

[33] J. G. Wells, STEM education: The potential of technology education. Council on Technology and Engineering Teacher Education, 2019. 
[34] P. Hartnett and R. Gelman, "Early understandings of numbers: Paths or barriers to the construction of new understandings?” Learning and Instruction, vol. 8, no. 4, pp. 341-374, 1998. https://doi.org/10.1016/s0959-4752(97)00026-1

[35] C. Acredolo, C. Understanding Piaget's new theory requires assimilation and accommodation. Human Development, vol. 40, no.4, 1997. https://doi.org/10.1159/000278 $\underline{726}$

[36] P. Kommers, A. IOS Press, Cognitive support for learning: Imagining the unknown. IOS Press, 2004.

[37] N. Yuruk, M. E. Beeth, and C. Andersen, "Analyzing the effect of meta conceptual teaching practices on students' understanding of force and motion concepts," Res. Sci. Educ., vol. 39, no. 4, pp. 449-475, 2009. https://doi.org/10.1007/s11165-008-9089-6

[38] M. Campbell, "The effects of the 5E learning cycle model on students' under-standing of force and motion concepts," Florida. Millersville University, 2006.

[39] A. O. Ajlouni, "The Effectiveness of an Instructional Program Based on Using Robot and Hypermedia in Acquiring Scientific Concepts and Developing Motivation Towards Learning Science among Fifth Grade Students in Jordan," University of Jordan, 2020.

[40] A. Merkouris, B. Chorianopoulou, K. Chorianopoulos, and V. Chrissikopoulos, "Understanding the notion of friction through gestural interaction with a remotely controlled robot," J. Sci. Educ. Technol., vol. 28, no. 3, pp. 209-221, 2019. https://doi.org/10.1007/ $\underline{\text { s10956-018-9760-2 }}$

[41] P. Ferrarelli et al., "Improving students' concepts about Newtonian mechanics using mobile robots," in Robotics in Education, Cham: Springer International Publishing, 2019, pp. 113124

[42] A. M. Kelly, "Teaching Newton's laws with the iPod Touch in conceptual physics," The Physics Teacher, vol. 49, no. 4, pp. 202-205, 2011. https://doi.org/10.1119/1.3566026

[43] N. Demirci, "A Study about Students' Misconceptions in Force and Motion Concepts by Incorporating a Web-Assisted Physics Program," Turkish Online Journal of Educational Technology-TOJET, vol. 4, no. 3, pp. 40-48, 2005.

[44] S. Papadakis and M. Kalogiannakis, "Learning Computational Thinking Development in Young Children with Bee-Bot Educational Robotics," M. Kalogiannakis and S. Papadakis, Eds. Hershey, PA: IGI Global, 2020, pp. 4018 978-1-7998-4576-8. https://doi.org/10. 4018/978-1-7998-4576-8.ch011

[45] M. E. Karim, S. Lemaignan, and F. Mondada, "A review: Can robots reshape K-12 STEM education?" in 2015 IEEE International Workshop on Advanced Robotics and its Social Impacts (ARSO), 2015. https://doi.org/10.1109/arso.2015.7428217

[46] D. Catlin, A. Csizmadia, J. O’Meara, and S. Younie, "Using Educational Robotics Research to Transform the Classroom Establishing a Robotics Community of Evidenced-Based Practice Using MESH Guides and the TACTICS Framework," 2015.

[47] C. Kim et al., "Studying the usability of an intervention to promote teachers' use of robotics in STEM education,” J. Educ. Comput. Res., vol. 56, no. 8, pp. 1179-1212, 2019.

[48] D. Catlin and M. Blamires, "Designing robots for special needs education," Technol. Knowl. Learn., vol. 24, no. 2, pp. 291-313, 2019. https://doi.org/10.1007/s10758-018-9378-8

[49] Y. J. Pang, H. Hussin, C. C. Tay, and S. S. S. Ahmad, "Robotics Competition-Based Learning for 21 st Century STEM Education,” Journal of Human Capital Development, vol. 12, no. 1, pp. 66-80, 2019.

[50] A. Oliveira, R. Feyzi Behnagh, L. Ni, A. A. Mohsinah, K. J. Burgess, and L. Guo, "Emerging technologies as pedagogical tools for teaching and learning science: A literature review," Human Behav and Emerg Tech, vol. 1, no. 2, pp. 149-160, 2019. https://doi.org/10.1002/ $\underline{\text { hbe } 2.141}$ 
[51] [25] S. Papadakis and M. Kalogiannakis, "Exploring preservice teachers' attitudes about the usage of educational robotics in Preschool Education," in Advances in Early Childhood and K-12 Education, IGI Global, 2020, pp. 339-355. https://doi.org/10.4018/978-1-7998-45768.ch013

[52] A. Eguchi, "Integrating educational robotics to enhance learning for gifted and talented students," in Human-Computer Interaction, IGI Global, 2015, pp. 1467-1495. https://doi.org/10.4018/978-1-4666-8789-9.ch071

[53] L. Athanasiou, T. A. Mikropoulos \& D. Mavridis, Robotics Interventions for Improving Educational Outcomes - A Meta-Analysis. In: Tsitouridou M., A. Diniz J., Mikropoulos T. (Eds) Technology and Innovation in Learning, Teaching, and Education. 2019. https://doi.org/10.1007/978-3-030-20954-4 7

[54] B. Falah and H. Noreddine, "Pedagogical Robotics-A Way to Experiment and Innovate in Educational Teaching in Morocco," International Journal of Education and Learning Systems, vol. 2, 2017.

[55] L. P. E. Toh, A. Causo, P. W. Tzuo, I. M. Chen, and S. H. Yeo, "A Review on the Use of Robots in Education and Young Children," Journal of Educational Technology \& Society, vol. 19, no. 2, pp. 148-163, 2016.

[56] D. Roy et al., "Inirobot: A Pedagogical Kit to Initiate Children to Concepts of Robotics and Computer Science," 2015.

[57] M. M. McGill, "Learning to program with Personal Robots: Influences on student motivation," ACM trans. comput. educ., vol. 12, no. 1, pp. 1-32, 2012.https://doi.org/10. $1145 / 2133797.2133801$

[58] J. M. Chambers and M. Carbonaro, "Designing, developing, and implementing a course on LEGO Robotics for technology teacher education," Journal of Technology and Teacher Education, vol. 11, no. 2, pp. 209-241, 2003.

[59] W. J. Church, T. Ford, N. Perova, and C. Rogers, "Physics with robotics-using LEGO MINDSTORMS in high school education," 2010.

[60] D. Scaradozzi, L. Screpanti, and L. Cesaretti, "Towards a definition of educational robotics: A classification of tools, experiences and assessments," in Smart Learning with Educational Robotics, Cham: Springer International Publishing, 2019, pp. 63-92. https://doi.org/10. 1007/978-3-030-19913-5_3

[61] D. Catlin, \& M. Blamires, M. The Principles of Educational Robotic Applications (ERA): A Framework for Understanding and Developing Educational Robots and Their Activities. 12th Eurologo Conference, Paris, 2010.

[62] S. Papadakis \& V. Orfanakis, The Combined Use of Lego Mindstorms NXT and App Inventor for Teaching Novice Programmers. In: Alimisis D., Moro M., Menegatti E. (Eds.), Educational Robotics in the Makers Era. Edurobotics. Advances in Intelligent Systems and Computing, vol 560, pp.193-204, 2017. https://doi.org/10.1007/978-3-319-55553-9_15

[63] M. Kalogiannakis and S. Papadakis, "Pre-service kindergarten teachers acceptance of 'ScratchJr' as a tool for learning and teaching computational thinking and science education," 2017, pp. 21-25.

[64] S. Papadakis, M. Kalogiannakis, V, Orfanakis, \& N. Zaranis. The Appropriateness of Scratch and App Inventor as Educational Environments for Teaching Introductory Programming in Primary and Secondary Education. International Journal of Web-Based Learning and Teaching Technologies, vol.12, no. 4, pp. 58-77, 2017. https://doi.org/10.4018/ijwltt. $\underline{2017100106}$ 
[65] S. Papadakis, M. Kalogiannakis, N. Zaranis, and V. Orfanakis, "Using Scratch and App Inventor for teaching introductory programming in secondary education. A case study," International Journal of Technology Enhanced Learning, vol. 8, no. 3-4, pp. 217-233, 2016. https://doi.org/10.1504/ijtel.2016.082317

[66] E. Reyes-Garcia, \& N. Bouhaï, N. Designing Interactive Hypermedia Systems. ISTE, Limited, 2017. https://doi.org/10.1002/9781119388272

[67] M.Tahmasebi, F. Fotouhi \& M. Esmaeili. Hybrid Adaptive Educational Hypermedia Recommender Accommodating User's Learning Style and Web Page Features. Journal of AI and Data Mining, vol. 7, no. 2, pp. 225-238, 2019.

[68] H. Bornman and S. H. von Solms, "Hypermedia, multimedia and hypertext: definitions and overview," Electron. libr., vol. 11, no. 4/5, pp. 259-268, 1993. https://doi.org/10.1108/ $\underline{\text { eb045243 }}$

[69] M. Lang and B. Fitzgerald, "Hypermedia systems development practices: A survey," IEEE Softw., vol. 22, no. 2, pp. 68-75, 2005. https://doi.org/10.1109/ms.2005.40

[70] J. Hayman, "Hypermedia: Portent of the future in informatics," High. Educ. Pol., vol. 5, no. 2, pp. 67-69, 1992.https://doi.org/10.1057/hep.1992.32

[71] E. De Vries, "Hypermedia for physics learning: The case of the energy concept," 2001, pp. 141-153.

[72] S. White and G. Reeves-Dearmond, "Reviving the Development of Hypermedia Resources for Historic Dress Courses,” 2017. https://doi.org/10.31274/itaa_proceedings-180814-399

[73] M. Hill, J. D. Bailey, and P. A. S. Reed, "Hypermedia systems for improving knowledge, understanding and skills in engineering degree courses," Comput. Educ., vol. 31, no. 1, pp. 69-88, 1998. https://doi.org/10.1016/s0360-1315(98)00019-0

[74] M. S. Żywno, "Hypermedia instruction and learning outcomes at different levels of Bloom's taxonomy of cognitive domain," Global J. of Engng. Educ, vol. 7, no. 1, pp. 59-70, 2003.

[75] L. Liu and C. E. Hmelo-Silver, "Promoting complex systems learning through the use of conceptual representations in hypermedia,” J. Res. Sci. Teach., vol. 46, no. 9, pp. 10231040, 2009. https://doi.org/10.1002/tea.20297

[76] M. Liu, "The effect of a hypermedia learning environment on middle school students' motivation, attitude, and science knowledge," Comput. Sch., vol. 22, no. 3-4, pp. 159-171, 2005. https://doi.org/10.1300/j025v22n03_13

[77] Conklin, "Hypertext: An Introduction and Survey," Computer (Long Beach Calif.), vol. 20, no. 9, pp. 17-41, 1987.

[78] J. Zumbach and M. Mohraz, "Cognitive load in hypermedia reading comprehension: Influence of text type and linearity," Comput. Human Behav., vol. 24, no. 3, pp. 875-887, 2008.https://doi.org/10.1016/j.chb.2007.02.015

[79] A. M. Shapiro, "Hypermedia design as learner scaffolding," Educ. Technol. Res. Dev., vol. 56, no. 1, pp. 29-44, 2008.

[80] R. Ruttun, "The Effects of Visual Elements and Cognitive Styles on Students' Learning in Hypermedia Environment," World Academy of Science, Engineering and Technology, vol. 49, pp. 963-971, 2009.

[81] A. Chatzopoulos, M. Kalogiannakis, M. Papoutsidakis, S. Psycharis, and D. Papachristos, "Measuring the impact on student's computational thinking skills through STEM and educational robotics project implementation," in Advances in Early Childhood and K-12 Education, IGI Global, 2020, pp. 238-288.https://doi.org/10.4018/978-1-7998-4576-8.ch010

[82] S. Kucuk and B. Sisman, "Students' attitudes towards robotics and STEM: Differences based on gender and robotics experience," International Journal of Child-Computer Interaction, vol. 100167, 2020. https://doi.org/10.1016/j.ijcci.2020.100167 
[83] B. Sisman, S. Kucuk, and Y. Yaman, "The Effects of Robotics Training on Children's Spatial Ability and Attitude toward STEM," International Journal of Social Robotics, vol. 1-11, 2020. https://doi.org/10.1007/s12369-020-00646-9

[84] [32] W. A. Alalawi and M. N. H. B. M. Said, "Using Lego Mindstorms Robotics Programming in Enhancing Computational Thinking among Middle School in Saudi Arabia," International Journal of Psychosocial Rehabilitation, vol. 24, no. 05, 2020. https://doi.org/10.37200/ijpr/v24i5/pr2020243

[85] N. Arís and L. Orcos, "Educational robotics in the stage of secondary education: Empirical study on motivation and STEM skills," Educ. Sci. (Basel), vol. 9, no. 2, p. 73, 2019. https://doi.org/10.3390/educsci9020073

[86] Ö. Korkmaz, The effect of scratch-and lego mindstorms Ev3-Based programming activities on academic achievement, problem-solving skills, and logical-mathematical thinking skills of students. Malaysian Online Journal of Educational Sciences, vol. 4, no. 3, pp.73-88, 2018.

[87] F. Kaloti-Hallak, M. Armoni \& M. Ben-Ari, Students' attitudes and motivation during robotics activities. In Proceedings of the Workshop in Primary and Secondary Computing Education, pp. 102-110, 2015.https://doi.org/10.1145/2818314.2818317

[88] F.-K. Chiang, Y.-Q. Liu, X. Feng, Y. Zhuang, and Y. Sun, "Effects of the world robot Olympiad on the students who participate: a qualitative study," Interact. Learn. Environ., pp. 112, 2020.https://doi.org/10.1080/10494820.2020.1775097

[89] D. Mavridis, Robotics Interventions for Improving Educational Outcomes - A Meta-analysis. In Technology and Innovation in Learning, Teaching and Education: First International Conference, (TECH-EDU), Thessaloniki, Vol. 993, Springer.2019. https://doi.org/10.1007/ 978-3-030-20954-4_7

[90] N. C. Zygouris, A. Striftou, A. N. Dadaliaris, G. I. Stamoulis, A. C. Xenakis, and D. Vavougios, "The use of LEGO Mindstorms in elementary schools," in 2017 IEEE Global Engineering Education Conference (EDUCON), pp. 514-516, 2017. https://doi.org/10.1109/ educon.2017.7942895

[91] A. Sullivan and M. U. Bers, "Robotics in the early childhood classroom: Learning outcomes from an 8-week robotics curriculum in pre-kindergarten through second grade," International Journal of Technology and Design Education, vol. 26, no. 1, pp. 3-20, 2016. https://doi.org/10.1007/s10798-015-9304-5

[92] A. Badeleh, "The effects of robotics training on students' creativity and learning in physics," Educ. Inf. Technol., 2019.

[93] K. Jaipal-Jamani and C. Angeli, "Effect of robotics on elementary preservice teachers' selfefficacy, science learning, and computational thinking," Journal of Science Education and Technology, vol. 26, no. 2, pp. 175-192, 2017. https://doi.org/10.1007/s10956-016-9663-z

[94] S. P. Krishnamoorthy and V. Kapila, "Using A visual programming environment and custom robots to learn C programming and K-12 STEM concepts," in Proceedings of the 6th Annual Conference on Creativity and Fabrication in Education, 2016. https://doi.org/10.1145/ $\underline{3003397.3003403}$

[95] J.-M. Sáez-López, M.-L. Sevillano-García, and E. Vazquez-Cano, "The effect of programming on primary school students' mathematical and scientific understanding: educational use of mBot," Educ. Technol. Res. Dev., vol. 67, no. 6, pp. 1405-1425, 2019. https://doi.org/10.1007/s11423-019-09648-5

[96] S. Marchisio, M. Plano, J. Ronco, and O. Von Pamel, "Introducing hypermedia learning resources in a Physics course on semiconductor devices for electronic engineering students," 2004. 
[97] B. D. Amin and A. Mahmud, "The Development of Physics Learning Instrument Based on Hypermedia and Its Influence on the Student Problem Solving Skill," Journal of Education and Practice, vol. 7, no. 6, pp. 22-28, 2016.

[98] G. W. Fulmer, "Validating proposed learning progressions on force and motion using the force concept inventory: Findings from Singapore secondary schools," Int. J. Sci. Math. Educ., vol. 13, no. 6, pp. 1235-1254, 2015. https://doi.org/10.1007/s10763-014-9553-x

[99] A. Savinainen \& J. Viiri. Using the Force Concept Inventory to characterise students' conceptual coherence. In Towards Meaningful Mathematics and Science Education, Proceeding on the IXX Symposium of Finnish Mathematics and Science Education Research Association. Bulletin of Faculty of Education, vol. 86, pp. 142-152, 2003. https://doi.org/10.1007/ $\underline{\text { s10763-007-9103-X }}$

[100] P. Ferrarelli et al., "Improving students' concepts about Newtonian mechanics using mobile robots," in Robotics in Education, Cham: Springer International Publishing, 2019, pp. 113124.

[101] J. C. Hayes and D. J. M. Kraemer, "Grounded understanding of abstract concepts: The case of STEM learning,” Cogn. Res. Princ. Implic., vol. 2, no. 1, p. 7, 2017.

[102] J. Schoenmaker and I. Stanchev, Principles and tools for instructional visualization. The Netherlands: University of Twente, 1994.

\section{$7 \quad$ Authors}

Aseel Ajlouni is Assistant Dean for Laboratories Affairs of the school of educational Sciences at the University of Jordan. She earned her PhD in Educational Technology from the University of Jordan, Jordan in 2020. Her research interests are in the area of instructional technology and digital signal processing. Email: a.ajlouni@ju.edu.jo

Suhair Jaradat is Associate Professor of Educational Technology in the Department of Curricula and Instruction at the University of Jordan. She earned her PhD in Educational Technology from the University of Missouri-St. Louis, USA, in 2004. She has published several research papers on integrating technology in the classroom, online teaching and learning, cognition and technology, and education for sustainability.

Article submitted 2020-09-14. Resubmitted 2021-03-24. Final acceptance 2021-03-25. Final version published as submitted by the authors. 